\title{
A Study Of A Feebate Policy Aimed At Vehicle Manufacturers To Reduce $\mathrm{CO}_{2}$ Emissions
}

Johann du Plooy, Stellenbosch University, South Africa Rudie Nel, Stellenbosch University, South Africa

\begin{abstract}
As part of environmental fiscal reform, the South African government introduced a vehicle emission tax during 2010. However, the design of this tax focuses on consumers and might not be as effective in reducing $\mathrm{CO}_{2}$ emissions. A feebate policy is considered as a possible alternative to reduce $\mathrm{CO}_{2}$ emissions. A literature review was performed on the topic of feebate policies that could encourage vehicle manufacturers to invest in energy-efficient technology aimed at reducing $\mathrm{CO}_{2}$ emissions. Based on the literature review a questionnaire was developed and distributed to nine vehicle manufacturers in South Africa. The study specifically focused on vehicle manufacturers as they have the opportunity to design, develop and introduce energy-efficient technology that could reduce $\mathrm{CO}_{2}$ emissions. Results suggest that a feebate policy (that leads to cost savings) is an alternative that could be considered to encourage vehicle manufacturers to invest in energy-efficient technology in order to reduce $\mathrm{CO}_{2}$ emissions.
\end{abstract}

Keywords: Feebate; Carbon Dioxide Emissions; South African Vehicle Manufacturers; Tax Incentives; Vehicle Emissions Tax

\section{INTRODUCTION}

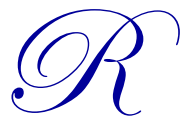

esearch conducted by the World Resources Institute (2000) indicated that carbon dioxide $\left(\mathrm{CO}_{2}\right)$ is the biggest contributor to greenhouse gas emissions. Furthermore, Schipper, Fabian and Leather (2009:1) found that the transport sector contributes $23 \%$ of all energy-related $\mathrm{CO}_{2}$ emissions globally, and Van Essen (2010:203) reported that both the energy and transport sectors are the only ones where $\mathrm{CO}_{2}$ emissions are rapidly increasing. Based on these research findings, there has been increased pressure to reduce $\mathrm{CO}_{2}$ emissions world-wide.

Vehicle manufacturers in particular experience pressure to accommodate change, and are faced with two clear but different issues: 1) improving energy efficiency and 2) reducing $\mathrm{CO}_{2}$ emissions (Rudman, 2008). Making vehicle energy efficient will be a challenge because extra costs need to be kept to a minimum in order for vehicles to remain attractive to consumers (Rudman, 2008). In addition, the disposable income of consumers is also affected by an increase in the fuel price, the implementation of vehicle emission tax, and the current economic climate. As a result, vehicle sales have plummeted and thousands of employees in the automotive industry have lost their jobs (Karrim, 2009). Although reducing $\mathrm{CO}_{2}$ emissions and improving energy efficiency are important, it is understandable that the priority in the automotive industry should be to safeguard jobs and maintain market interest. Funding from government could serve as a means by which jobs can be preserved and, if funding is sufficient, could also fund additional investment in technology aimed at reducing $\mathrm{CO}_{2}$ emissions and more efficient fuel technology.

Under the new Automotive Production and Development Plan (APDP) that was announced in September 2008, the South African National Treasury allocated funding to the tune of R870 million to the automotive industry in the form of production subsidies over three years (Karrim, 2009). The APDP replaces the motor industry development plan and is aimed at facilitating growth, increasing production, creating employment and encouraging 
investment in the local motor vehicle industry over time (Karrim, 2009). This is undoubtedly a significant allocation, but considering the current economic climate, these funds will most likely first be allocated toward securing jobs and maintaining sales. These production subsidies were not specifically earmarked to be invested in reducing $\mathrm{CO}_{2}$ emissions. Therefore, further initiatives should be considered to reduce $\mathrm{CO}_{2}$ emissions in the automotive industry, which includes vehicle manufacturers.

Incentive initiatives to vehicle manufacturers for investing in reducing $\mathrm{CO}_{2}$ emissions could be achieved by the following means:

- $\quad$ direct funding from government to invest in $\mathrm{CO}_{2}$ emission reduction

- allowing tax deductions for expenses incurred to invest in $\mathrm{CO}_{2}$ emission reduction in terms of the Income Tax Act No. 58 of 1962 (Act)

Direct funding from government could be facilitated by the recently implemented vehicle emission tax (environmental levy) imposed on new passenger vehicles manufactured in, or imported into, South Africa from 1 September 2010 (RSA, 2010). The vehicle emission tax is based on the amount of $\mathrm{CO}_{2}$ emissions per vehicle. The purpose of this tax is to deter consumers from acting in a manner that is not in the best interest of the environment. Therefore, it would attempt to influence consumers' purchasing decisions (by encouraging the purchase of vehicles with lower $\mathrm{CO}_{2}$ emissions), but because of the focus on consumers, on its own it might not be the most effective way of reducing $\mathrm{CO}_{2}$ emissions (Nel, 2009:73). In order to give effect to the highest possible reduction in $\mathrm{CO}_{2}$ emissions an alternative could be to earmark the funds raised in terms of the new vehicle emission tax for subsequent distribution to vehicle manufacturers to invest in reducing $\mathrm{CO}_{2}$ emissions. Energy Minister, Mr. Dipuo Peters, also suggested that taxes might be used to fund initiatives that reduce $\mathrm{CO}_{2}$ emissions (Salgado, 2011). In doing so, a feebate policy would be implemented as envisaged by Greene, Patterson, Singh and Li (2005:758).

This feebate policy involves both additional fees/taxes (in this case, the vehicle emission tax) as well as rebates/incentives (in this case, the funding provided to vehicle manufacturers). According to Greene et al. (2005:758), such a feebate policy, which is revenue-neutral toward government, could also have the additional benefit of improving the perception of the public toward the tax levied. Davis, Levine, Train and Duleep (1995) also recommended that future research be performed regarding the sensitivity of vehicle manufacturers' response to "feebates" in terms of the cost of fuel-economy technologies. The feebate policy considered in this study is illustrated in Figure 1.

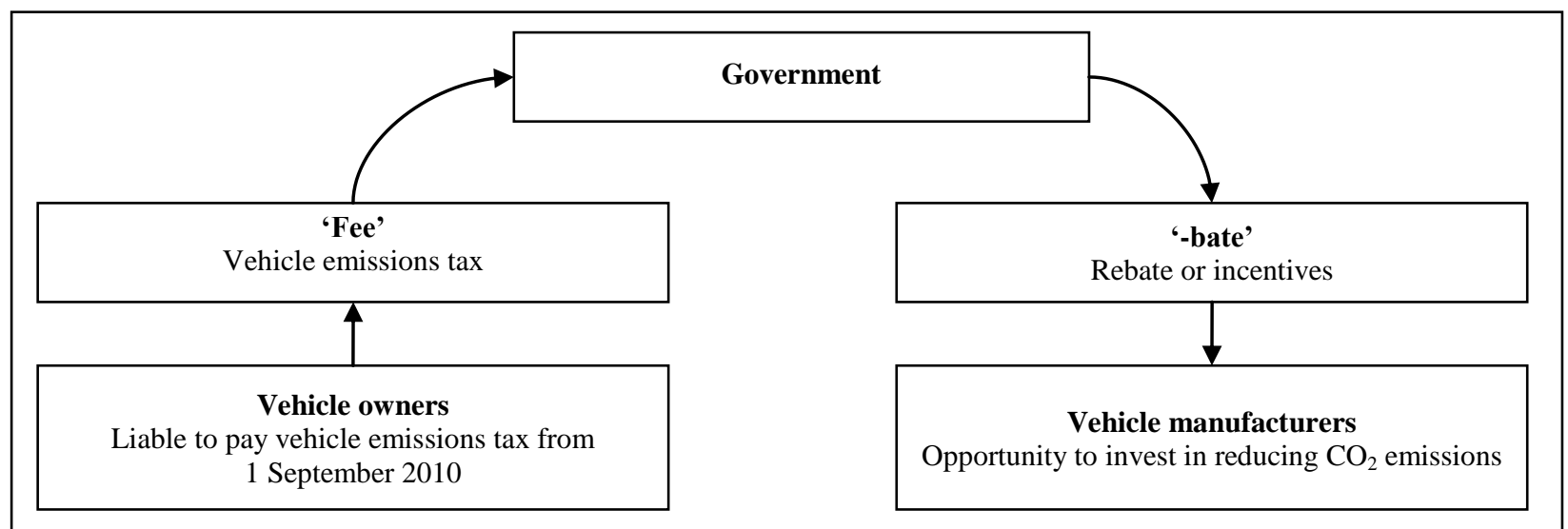

Figure 1: Illustration Of The Feebate Policy Considered In This Study

In contrast to a feebate policy (direct funding), the Income Tax Act could also allow, subject to specific requirements, expenditure to be deducted when calculating taxable income. It is also proposed that investments by companies in energy-efficient equipment should qualify for an additional allowance of up to $15 \%$, but an effective date is still to be determined (SARS, 2009:9). For automobile manufacturers to qualify for these tax incentives, a fair 
amount of time, ingenuity, and financial investment is required right away with some of the tax benefits only realized over a period (i.e., accelerated allowances on assets in terms of Section 12B). Thus, for the purposes of this study, these incentives were not considered.

Due to the need identified for alternative initiatives to reduce $\mathrm{CO}_{2}$ emissions, this research was conducted. The main objective of the study was to investigate the possible implementation of a feebate policy to reduce $\mathrm{CO}_{2}$ emissions in the South African automotive industry. The focus was on vehicle manufacturers in South Africa and qualitative evidence was obtained by means of a questionnaire. Based on results of the study, we concluded whether such a policy is acceptable to vehicle manufacturers and how they perceive such a policy as an incentive to reduce $\mathrm{CO}_{2}$ emissions in the automotive industry.

\section{RESEARCH METHODOLOGY}

A literature review was performed on feebate policies that could encourage vehicle manufacturers to invest in reducing $\mathrm{CO}_{2}$ emissions. The literature review formed a basis for this study to understand the objectives and to develop questions for a questionnaire. Other questions were adapted from a survey performed by PwC (2010) and reworded for this study to ensure that the questions were relevant to vehicle manufacturers and that they would meet the objectives.

A questionnaire was circulated in order to explore the attitudes and views of vehicle manufacturers regarding the possible implementation of a feebate policy to reduce $\mathrm{CO}_{2}$ emissions. The questionnaire was distributed to nine vehicle manufacturers as per the National Association of Automobile Manufacturers of South Africa (NAAMSA) as all major manufacturers of vehicles are registered with NAAMSA (NAAMSA, 2010). The study specifically focused on these vehicle manufacturers in South Africa as they have the opportunity to design, develop, and manufacture efficient technology with regard to fuel efficiencies, which could reduce $\mathrm{CO}_{2}$ emissions.

Upon receipt of the responses, the data were analysed in order to investigate the possible implementation of a feebate policy to reduce $\mathrm{CO}_{2}$ emissions in the South African automotive industry, specifically focusing on vehicle manufacturers.

Due to the nature of this study, the manner in which the questions were formulated was very important for meeting the objectives; therefore, the participants had to find them easy to understand. Since it was expected that the participants would also have accounting backgrounds, the questionnaire was also given to several accountants for review to ensure that the questions were clear to them.

The questionnaire was also submitted to the Centre for Statistical Consultation at Stellenbosch University where specialists in the use of questionnaires and the interpretation of data reviewed it to ensure that the questions were properly formulated and that the data obtained from it would therefore be relevant and usable for this study.

\section{LITERATURE REVIEW}

Since $\mathrm{CO}_{2}$ emissions are increasing globally in the transport sector, it has become vital to introduce additional policies to reduce these emissions. Several different policies can be used to reduce $\mathrm{CO}_{2}$ emissions. The study performed by DeCicco (2006) suggests that $\mathrm{CO}_{2}$ emissions could be reduced by encouraging consumers to use energy-efficient vehicles and informing them in this regard. However, other authors (Greene et al., 2005; Nel, 2009; Hayashi et al., 2001) also emphasised the role of vehicle manufacturers in reducing $\mathrm{CO}_{2}$ emissions. The focus should therefore not only be on encouraging consumers to change their behaviour, but also on encouraging vehicle manufacturers to improve energy-efficient vehicles.

To encourage vehicle manufacturers to invest in researching and developing energy-efficient vehicles, they need to be rewarded for such behaviour. Mainstream businesses in South Africa are of the opinion that legislation, potential cost savings and managing business reputation are some of the leading factors that influence decisionmaking when it comes to changing behaviour in favour of the environment (Van der Merwe, 2010). In order to influence decision-making to reduce $\mathrm{CO}_{2}$ emissions, government could either legislate policies (require compulsory 
participation) or introduce policies that could lead to cost savings (encourage participation). The following sections consider legislation and cost-saving policies and the way a feebate policy could assist in addressing the leading factors that influence decision-making in order to reduce $\mathrm{CO}_{2}$ emissions.

\section{Policies in the Form of Legislation (Compulsory Participation)}

The hardest things to change in business and in individuals are behaviour and thinking regarding climate change (Paul, 1997:118). Van der Merwe (2010) explained this in an article on a report by PwC ("Appetite for change: global business perspectives on tax and regulation for a low carbon economy") that businesses are mostly influenced to change behaviour in favour of the environment when there are policies introduced by government in the form of legislation and regulation. Furthermore, a policy that can address the behaviour of both consumers and vehicle manufacturers would be ideal. In this section, South African policies that will affect consumers and vehicle manufacturers alike are considered.

\section{Policies Aimed at Consumers}

South African government-driven policies that may affect consumers' behaviour to reduce $\mathrm{CO}_{2}$ emissions can be categorised as ownership taxes, purchase taxes and usage taxes. According to Hayashi, Kato and Val (2001:135-138), usage tax is most effective in reducing $\mathrm{CO}_{2}$ emissions as consumers drive shorter distances and have more efficient driving habits. Ownership tax affects consumer behaviour by convincing them to buy smaller vehicles that have less $\mathrm{CO}_{2}$ emissions, thereby reducing the cost of owning the vehicle. Purchase tax was found to have very little influence on reducing $\mathrm{CO}_{2}$ emissions (Hayashi et al., 2001:135-138).

The South African vehicle emissions tax, introduced on 1 September 2010, can be seen as purchase tax. The main purpose of vehicle emissions tax is to reduce $\mathrm{CO}_{2}$ emissions through taxing the consumer based on the $\mathrm{CO}_{2}$ emissions output per passenger vehicle in an attempt to affect consumer behaviour (discouraging the purchase of vehicles that emit higher $\mathrm{CO}_{2}$ ). However, $\mathrm{CO}_{2}$ is only emitted when a vehicle is driven, which consequently affects the fairness of the tax, as a buyer of a small vehicle who drives $10,000 \mathrm{~km}$ per year pays the same amount of tax as a buyer who drives $100,000 \mathrm{~km}$ per year (Osborne, 2010). As indicated, this purchase tax will not necessarily have the desired effect of reducing $\mathrm{CO}_{2}$ emissions, confirming what Hayashi et al. (2001) stated; namely, that vehicle emission tax might not be as effective as ownership and usage taxes.

At present in South Africa, ownership taxes include license fees (including VAT) and toll fees. License fees are charged annually and are based on the weight of the vehicle, but do not take the environment into consideration (Nel, 2009:46) and they do not include a levy relating to environmental concerns (such as $\mathrm{CO}_{2}$ emissions). Kunert and Hartmut (2007:307) argue that if license fees are increased to account for energy-insufficient vehicles, it is classified as ownership tax. Hayashi et al. (2001:135-138) maintain that, although ownership taxes are more effective than purchase taxes, the increase in ownership taxes to accommodate environmental considerations will not produce the desired result and that usage taxes are therefore more effective in this regard.

Usage taxes in South Africa consist mainly of transport levies, with a few insurance companies that have introduced pay-as-you-drive insurance (which includes VAT). Transport levies consist of the general fuel levy, the Road Accident Fund levy, the customs and excise levy, and the Illuminating Paraffin Marker levy (SARS, 2009:15). Fuel levies are, however, not directly levied based on environmental concerns (such as $\mathrm{CO}_{2}$ emissions). Hayashi et al. (2001:135-138) contend that fuel levies are the most effective taxes to reduce $\mathrm{CO}_{2}$ emissions. According to Nel and Nienaber (2012), further increases in fuel levies in an attempt to reduce $\mathrm{CO}_{2}$ emissions might not be the most preferred option in South Africa.

Currently in South Africa, the vehicle emissions tax (purchase) is the only tax directly linked to the reduction of $\mathrm{CO}_{2}$ emissions. Ownership and usage taxes in South Africa are not currently used to affect $\mathrm{CO}_{2}$ emissions (Nel \& Nienaber, 2012). Moreover, these policies only focus on changing the behaviour of the consumer and not so much on changing the behaviour of the manufacturer. 


\section{Policies Aimed at Vehicle Manufacturers}

Indirectly, the policies that affect consumer behaviour, such as the purchase, usage and ownership taxes, could have an effect on the vehicle manufacturer, as the demand for more energy-efficient vehicles could drive the type of vehicles that are manufactured. However, currently there are no direct legislation policies in South Africa that require vehicle manufacturers to reduce $\mathrm{CO}_{2}$ emissions. A feebate policy might achieve this desired change.

\section{Policies that Lead to Cost Saving (Encouraged Participation)}

Findings by Nel (2009:22) have led to the conclusion that policies in the form of legislation (compulsory participation) might not be as effective in reducing $\mathrm{CO}_{2}$ emissions as investing in technology that would lead to energy-insufficient vehicles. Osborne (2010), the CEO of the Retail Motor Industry organisation (RMI), argued that instead of taxing consumers, government needs to introduce incentives in the vehicle market that could lead to $\mathrm{CO}_{2}$ emission reductions.

According to Hayashi, Button and Nijkamp (1999), there are policies to give incentives in order to develop vehicles with low $\mathrm{CO}_{2}$ emissions, and they are working. Hayashi et al. (2001:125-126) also indicated that policies that are incentive-driven will persuade vehicle manufacturers to favour low $\mathrm{CO}_{2}$ emission alternatives by researching and developing low emission type vehicles. Van der Merwe (2010), who asserts that business favours environmental tax incentives, supports this view. According to Van der Merwe (2010), businesses feel the answer to implementing such a policy lies in a combination of "carrot and stick" - tax incentive and regulation; therefore, a policy that will reward low $\mathrm{CO}_{2}$ emissions and penalise high $\mathrm{CO}_{2}$ emissions should be implemented.

Johnson (2006:3115-3118), who studied a cap-and-trade policy with a refunded emission tax, concluded that a cap-and-trade policy together with a refunded emission tax, which is an incentive, would be more likely to reduce $\mathrm{CO}_{2}$ emissions than just the cap-and-trade. He found that a cap-and-trade policy only caps $\mathrm{CO}_{2}$ emissions at a specific level, whereas an incentive in the form of refunded emission tax could create a climate of stable investments with sustained incentives for reduced $\mathrm{CO}_{2}$ emissions over the long term. Johnson (2006) concluded that a policy where a tax is levied, which is distributed as an incentive, could lead to reducing $\mathrm{CO}_{2}$ emissions significantly in the transport industry.

The incentives that are distributed could be used by manufacturers to cover the cost of investments in research and the development of energy-efficient vehicles. As explained, cost savings is a factor that influences decision-making when it comes to changing behaviour in favour of the environment; therefore, a policy that can bring about cost savings needs to be introduced by government to change behaviour toward the environment.

Current South African policies in the automotive industry where incentives are provided relate to the export of vehicles (Black \& Mitchell, 2002), facilitating growth, increasing production, creating employment and encouraging investment in the local motor vehicle industry (Karrim, 2009). These incentives lead to cost savings for their intended purposes, but they do not relate to cost savings in the research and development of energy-efficient vehicles.

Other incentives from government, as stipulated in the Income Tax Act, are in the form of tax allowances and deductions. However, there is no direct funding that leads to cost savings in terms of the research and development of energy-efficient vehicles. Van der Merwe (2010) claims that businesses feel that the criteria to qualify for current environmental tax incentives are too stringent and that these incentives do not motivate businesses sufficiently to change behaviour. Thus, incentives in South Africa that can lead to cost savings for vehicle manufacturers are needed to change their behaviour toward the environment.

A feebate policy could bring about cost savings for vehicle manufacturers which could lead to a change in manufacturers' behaviour. A feebate implies that additional taxes (fees) are levied and distributed as incentives (rebates). For the purposes of this study, the fees that need to be raised for a feebate policy are the taxes raised by government which, in South Africa, is the vehicle emission tax introduced on 1 September 2010 (RSA, 2010). 
The implementation of the vehicle emission tax will result in increased funds for the South African government. As reports have shown, the National Treasury expected to earn about R450 million in the 2010/2011 financial year from the vehicle emission tax that was introduced (Osborne, 2010). Alternative funds can also be generated if the transport fuel levies (usage taxes) and ownership taxes are increased to incorporate $\mathrm{CO}_{2}$ in the assessment base (Paul, 1997). These increased funds could be earmarked specifically for the investment in reducing $\mathrm{CO}_{2}$ emissions and could serve as a source of funding to provide incentives for the automotive industry to invest in the reduction of $\mathrm{CO}_{2}$ emissions. Thus, costs can be saved by manufacturers, which could lead to a change in favour of the environment if a "feebate policy is used.

\section{The Merit of A Feebate Policy}

In South Africa, there is currently no feebate policy or one that is similar. Several studies have been conducted on feebate policies in other countries. Greene et al. (2005:758-759) argued the merit of a feebate policy in the United States of America (USA). Peters, Mueller, De Haan and Scholz (2008:1364) suggest that public acceptance for a feebate policy in Europe is comparatively high and they add that when the changes are considered within a disaggregated car fleet, a reduction in $\mathrm{CO}_{2}$ emissions will prevail. They also contend that the design and detail function of a feebate policy does not need to be completely understood by people, but the mere fact that it can be seen as a policy that will reduce $\mathrm{CO}_{2}$ emissions is acceptable to the public. Osborne (2010) and Van der Merwe (2010) state that, in South Africa, business regards incentive-driven policies (which would include a feebate policy) as being necessary for changing behaviour toward the environment.

The following are some of the possible benefits of a "feebate" policy:

- It has the potential to maintain, or even increase, the vehicle manufacturers' revenues with the added benefit of providing a continuous incentive to improve fuel technologies (Greene et al., 2005:770-771).

- It could possibly be the most effective policy to be implemented in order to reduce fuel consumption and carbon dioxide emissions (Greene et al., 2005:758).

- If the feebate policy is made revenue-neutral, it could improve taxpayers' attitudes toward taxes levied for environmental concerns (for example, vehicle emission tax). It would not be perceived as being only an income-generating tool (Greene et al., 2005:771).

- The appeal of a feebate policy lies in the fact that the policy can take care of the rebate (incentive) and the administrative costs (Bandivadekar, 2008:25).

- $\quad$ The feebate policy would provide a continuous incentive for manufacturers to improve on fuel economy technologies. It could provide an ever-present extra incentive to increase fuel economy whenever new, more cost-effective technologies are identified (Greene et al., 2005:758).

- $\quad$ A study by Davis et al. (1995, cited in Greene et al., 2005:759) in the USA consistently found that manufacturers' adoption of "fuel economy technology" accounted for about $90 \%$ of the overall increase in fuel economy brought about by feebate policies.

- A feebate policy will also influence consumers' behaviour to be environmentally friendly on account of the vehicle emission tax that is raised.

- $\quad$ A feebate policy in South Africa can lead to cost savings in designing energy-efficient vehicles which will make the South African automotive industry more competitive globally. Cost savings can also help with the safeguarding of jobs as money can be saved on the design of the vehicle instead of on retrenching workers.

Paul (1997:126) noted that the biggest obstacle to implementing a policy that would lead to reduced $\mathrm{CO}_{2}$ emissions is neither economic nor technical, but political. Implementing a policy aimed at addressing environmental concerns could play a major role in the way the public views government's ability to address the current economic situation or the way government responds to climate change.

Furthermore, implementing a policy to respond to climate change requires adequate collaboration between relevant parties, specifically vehicle manufacturers. The next section explores the ideas and sentiments of vehicle manufacturers regarding a feebate policy to invest in the reduction of $\mathrm{CO}_{2}$ emissions. 


\section{FINDINGS BASED ON EMPIRICAL EVIDENCE OBTAINED FROM QUESTIONNAIRE}

In this section, the findings based on empirical evidence found in the questionnaire are discussed. The questionnaire was divided into the following two sections for which findings will be discussed separately:

- $\quad$ investigating the possible implementation of a feebate policy to reduce $\mathrm{CO}_{2}$ emissions

- $\quad$ general comments received from South African vehicle manufacturers

\section{Investigating the Possible Implementation of A Feebate Policy to Reduce $\mathrm{CO}_{2}$ Emissions}

Mainstream businesses in South Africa argue that legislation, potential cost savings, and managing business reputation are some of the leading factors that influence decision-making when it comes to changing behaviour in favour of the environment (Van der Merwe, 2010), thus these policies may be instrumental in changing vehicle manufacturers' behaviour toward the environment in reducing $\mathrm{CO}_{2}$ emissions.

The following sections reflect the views of the vehicle manufacturers who participated in the questionnaire regarding policies in the form of legislation (compulsory participation) and policies that lead to cost savings (encouraged participation).

\section{Policies in the Form of Legislation (Compulsory Participation)}

Responses to the questionnaire indicated that the vehicle manufacturers were convinced that government should have the primary responsibility for leading behavioural change in relation to reducing $\mathrm{CO}_{2}$ emissions in the automotive industry. All the respondents agreed that government should be involved and 57\% indicated that a combination of business, government and individuals should share in the responsibility of leading behavioural change in relation to reducing $\mathrm{CO}_{2}$ emissions in the automotive industry.

These findings are in agreement with the statement by Van der Merwe (2010) that government should help drive change toward the environment by reducing $\mathrm{CO}_{2}$ emissions. Vehicle manufacturers responded on the perceived effectiveness of different tools (regulation, tax charges and tax incentives) that government can use to reduce $\mathrm{CO}_{2}$ emissions.

The majority of respondents agreed that regulation and tax charges would only be somewhat effective in encouraging them to reduce $\mathrm{CO}_{2}$ emissions. This confirms the results of the survey by $\mathrm{PwC}$ (2010), but also those of the questionnaire that are reported in this article - companies felt that tax incentives are even more effective than regulation and tax charges. The findings summarised in Table 1 are evidence of this view, as the majority of South African vehicle manufacturers $(71 \%)$ indicated that they considered tax incentives to be the most effective tool to encourage businesses to reduce $\mathrm{CO}_{2}$ emissions. It is therefore suggested that government could introduce an incentive-driven policy as an alternative method to drive change in the automotive industry in order to develop energy-efficient technology to reduce $\mathrm{CO}_{2}$ emissions. As explained previously, a feebate policy is an incentivedriven policy which government could use to achieve this aim. However, it is important that government properly regulate an incentive-driven policy as regulation can also play an important role in achieving targets on $\mathrm{CO}_{2}$ emissions. Vehicle manufacturers responded on the role of regulation in achieving targets $\mathrm{CO}_{2}$ emissions as indicated in the Table 2.

Table 1: Effective Tools to Reduce $\mathrm{CO}_{2}$ Emissions

\begin{tabular}{|l|c|c|c|}
\hline \multicolumn{1}{|c|}{ Tools } & Not Effective & Somewhat Effective & Very Effective \\
\hline Regulation & $29 \%$ & $71 \%$ & $0 \%$ \\
\hline Tax charges & $0 \%$ & $86 \%$ & $14 \%$ \\
\hline Tax incentives & $0 \%$ & $29 \%$ & $71 \%$ \\
\hline
\end{tabular}


Table 2: The Role of Regulation in Achieving Targets on $\mathrm{CO}_{2}$ Emissions

\begin{tabular}{|l|c|c|c|}
\hline \multicolumn{1}{|c|}{ Regulation } & No Role & Some Role & Significant Role \\
\hline Tax regulation & $0 \%$ & $43 \%$ & $57 \%$ \\
\hline Other regulation & $0 \%$ & $71 \%$ & $29 \%$ \\
\hline
\end{tabular}

Vehicle manufacturers indicated that they felt that regulation can help them achieve $\mathrm{CO}_{2}$ emission targets if those were set by government. The majority were of the view that tax regulation could be more effective in achieving these targets. This is in line with findings from the study done by $\mathrm{PwC}$ where $95 \%$ of companies interviewed around the world agreed that regulation and tax could play some role in achieving targets on national greenhouse gas emissions. In the same questionnaire, 68\% of carbon taxpayers were supporting carbon taxes (PwC, 2010). They felt that taxes were an effective tool to be used in reducing greenhouse gas emissions.

The findings of the current questionnaire indicate that $71 \%$ of vehicle manufacturers in South Africa support carbon tax in the form of vehicle emission tax payable by consumers. These manufacturers maintained that some strategy had to be put in place to change their behaviour toward the environment. Although the respondents supported the vehicle emission tax, they were of the opinion that a vehicle emission tax would not have the desired effect of reducing $\mathrm{CO}_{2}$ emissions. Their reasons were that:

- the quality of fuel in South Africa needs to improve, otherwise the reduction in $\mathrm{CO}_{2}$ emissions through vehicle emission tax will not have the desired effect

- the administration process related to the vehicle emission tax should also be improved to make it more effective

One of the respondents, who did not support the vehicle emission tax, was involved in discussions with the Department of Trade and Industry as well as the National Treasury and said it had become clear that the vehicle emission tax is merely another tax burden under the guise of 'going green'. Thus, when government designs an incentive-driven policy, it will have to be clear from the outset that it is not just another way of collecting tax, but that it is revenue-neutral. Greene et al. (2005:759) stated that a feebate policy is revenue-neutral and that it could increase taxpayers' confidence in the policy as it would not be perceived to be an income-generating exercise from government.

Greene et al. (2005:759) concluded that a feebate policy that it is revenue-neutral could increase taxpayers' confidence toward the policy as it would not be perceived to be an income-generating exercise from government. Vehicle manufacturers were asked, in the questionnaire, whether they would perceive a feebate policy to be just another attempt by government to generate income of which their responses are indicated in Table 3.

Table 3: Perceptions of Vehicle Manufacturers of A Feebate Policy as Just Another Tax

\begin{tabular}{|c|c|c|c|}
\hline Question & Yes & No & Do not know \\
\hline Would you perceive a feebate policy as just another tax? & $43 \%$ & $28 \%$ & $29 \%$ \\
\hline
\end{tabular}

The responses received indicate that vehicle manufacturers may perceive a feebate policy as just another tax. Consequently, it is suggested that if a feebate policy is implemented in South Africa, the government should promote transparency and clearly explain to vehicle manufacturers that the purpose is not to create another means of generating tax but that it is revenue-neutral and can lead to cost savings for vehicle manufacturers.

\section{Policies that Lead to Cost Savings (Encouraged Participation)}

Vehicle manufacturers experience pressure to accommodate change and are faced with the challenge of developing energy-efficient technology to reduce $\mathrm{CO}_{2}$ emissions (Rudman, 2008:15). It would be challenging to make vehicles energy efficient because of the additional cost in the form of research and development. These costs need to be kept to a minimum as "green" vehicles should be attractive to consumers (Rudman, 2008:15). This will be difficult without alternative funding as changes need to take place in the automotive industry to develop energyefficient technology. 
All respondents agreed that there would be change in the way they conduct business as a result of $\mathrm{CO}_{2}$ emissions over the next two to three years. The changes they envisaged pointed to investing in technology that could reduce $\mathrm{CO}_{2}$ emissions as vehicle manufacturers are encouraged worldwide to do so. Respondents also indicated that because the vehicle emission tax had been introduced, they needed to invest in their vehicles so that they would have less $\mathrm{CO}_{2}$ emissions.

Investing in energy-efficient technology will inevitably lead to increased costs for vehicle manufacturers. As previously highlighted, cost savings for businesses are instrumental in changing behaviour. To achieve cost savings, government could introduce incentives that are aimed at reducing $\mathrm{CO}_{2}$ emissions in the automotive industry. Osborne (2010), the CEO of the RMI, argued that instead of taxing consumers, government needs to introduce incentives in the vehicle market that could lead to $\mathrm{CO}_{2}$ emission reductions. These incentives could be funded from taxes already raised to address $\mathrm{CO}_{2}$ emissions. All the respondents agreed that it is important that funds be raised from environmental taxes and that regulation needs to be directed at environmental projects and initiatives. Of the respondents, $86 \%$ were supportive of government earmarking the vehicle emission tax as an incentive to invest in $\mathrm{CO}_{2}$ emission-reduction initiatives. They also agreed that government needs to offer more incentives to vehicle manufacturers to support investment in $\mathrm{CO}_{2}$ emission reduction.

Although vehicle manufacturers support incentives to reduce $\mathrm{CO}_{2}$ emissions, it will not be beneficial to them as research and development are done by the parent company that is situated in developed countries. According to Hayashi et al. (2001:125-126), policies that are incentive-driven will persuade vehicle manufacturers to favour low $\mathrm{CO}_{2}$ emission alternatives by researching and developing low-emission-type vehicles. A possible spin-off of introducing an incentive in the automotive industry could encourage vehicle manufacturers to do research and development in South Africa, which could also bring about more investment and job creation.

Presently in South Africa, there are not sufficient tax incentives for investment in $\mathrm{CO}_{2}$ emission reduction. Eighty-six percent of vehicle manufacturers disagreed with the statement that current tax incentives for investment in $\mathrm{CO}_{2}$ emission reductions are sufficiently motivating to make businesses change their behaviour. Therefore, an incentive-driven policy in South Africa could be implemented to motivate businesses to change their behaviour in favour of the environment if the necessary incentives are provided. A feebate policy is an incentive-driven policy as it could motivate businesses to change their behaviour toward the environment.

All of the respondents believed that it is a good idea for a tax system to include incentives for businesses to become carbon-neutral and $86 \%$ of the respondents indicated that these incentives could encourage them to make further investments in reducing $\mathrm{CO}_{2}$ emissions.

\section{General Comments Received from South African Vehicle Manufacturers}

Vehicle manufacturers worldwide feel the pressure to accommodate change to reduce $\mathrm{CO}_{2}$ emissions (Rudman, 2008:15). One respondent said that vehicle manufacturers world-wide are encouraged to change in order to be more environmentally friendly, but these changes are costly and could lead to increased prices of vehicles. Of the vehicle manufacturers in South Africa, 86\% expect to comply with future $\mathrm{CO}_{2}$ emission initiatives, which could hold a significant cost for their business. Research and development are expensive and incurring these costs will require expensive changes to their infrastructure. Vehicle manufacturers said that they would have to absorb all these costs and that it could increase the selling price of vehicles.

Although the changes are costly, $70 \%$ of vehicle manufacturers stated that their company was already investing in ways to reduce $\mathrm{CO}_{2}$ emissions, thus conducting research and development. Respondents indicated that it is unfortunate that most of the research and development takes place in developed countries where the tax systems drive $\mathrm{CO}_{2}$ reduction and that the tax system in South Africa does not do that. An incentive-driven policy aimed at local vehicle manufacturers is needed to help accommodate change in the automotive industry and to reduce the cost of research and development of energy-efficient technology. A feebate policy could drive change and save costs in order to reduce $\mathrm{CO}_{2}$ emissions. It appears from the feedback from vehicle manufacturers that they will welcome an incentive-driven policy that could bring about a reduction in $\mathrm{CO}_{2}$ emissions. 
Vehicle manufacturers also mentioned some other initiatives that could reduce $\mathrm{CO}_{2}$ emissions:

- $\quad$ The fuel price should include a portion of $\mathrm{CO}_{2}$ tax. They said that everybody who pollutes must pay. They explained that it is an easier mechanism in the long term to collect tax. Funds collected in this manner could possibly be redistributed as incentives.

- $\quad$ South Africa's fuel quality needs to be improved which could also help with reducing $\mathrm{CO}_{2}$ emissions.

- $\quad$ Once fuel quality has been resolved, original equipment manufacturers can bring already developed, more fuel-efficient vehicles into the country. Therefore, lower vehicle emission tax will have to be paid by the consumer.

- $\quad$ More focus could be placed on selling fuel-efficient vehicles.

\section{CONCLUSION}

Both Greene et al. (2005:758) and Nel (2009:73) have indicated that a feebate policy can be a possible alternate initiative to reduce $\mathrm{CO}_{2}$ emissions. The results of this study suggest that vehicle manufacturers favour an incentive-driven policy to introduce change in behaviour toward the environment. Vehicle manufacturers remarked that government should take primary responsibility for introducing an incentive-driven policy. However, even if government should take primary responsibility for introducing an incentive-driven policy, there should be adequate collaboration between relevant parties, specifically vehicle manufacturers, when considering implementing a feebate policy. Such an incentive-driven policy could encourage and motivate manufacturers to invest in energy-efficient technology, thereby saving costs and producing environmentally friendly vehicles. A feebate policy is an incentivedriven policy that can achieve these results.

Forty-three percent of the respondents indicated that a feebate policy might be perceived as just another tax. This perception could, however, be changed if government effectively communicates to vehicle manufacturers that the purpose is not to create another means of generating tax but that it is revenue-neutral and can lead to cost savings for vehicle manufacturers. An added benefit of a feebate policy is that, if properly implemented, it could be revenueneutral toward government and that it could increase taxpayers' confidence in government and in such a policy. By implementing a feebate policy, government could also show its commitment to reinvest in environmental projects.

By implementing a feebate policy government should be able to generate funds to distribute as incentives to vehicle manufacturers. The recently introduced vehicle emission tax could provide possible funding as reports showed that National Treasury expects to earn about R450 million in the 2010/2011 financial year (Osborne, 2010). Alternative funds can also be generated if the transport fuel levies (usage taxes) and ownership taxes are increased to incorporate $\mathrm{CO}_{2}$ in the assessment base (Paul, 1997). Therefore, funds ("fees") should be available for government and they should formulate the criteria for qualifying for incentives to invest in energy-efficient technology to reduce $\mathrm{CO}_{2}$ emissions. Implementing a feebate policy could be a possibility because, in terms of such a policy, the criteria for investing in energy-efficient technology would be included and should then be communicated to vehicle manufacturers.

At the end of the day, the most effective fiscal reform initiative to reduce $\mathrm{CO}_{2}$ emissions and conserve the environment may not be one where people are forced to contribute; rather, people should be encouraged to contribute and be rewarded when they contribute. The feebate policy recommended in this study could possibly provide such an incentive to vehicle manufacturers to invest in the reduction of $\mathrm{CO}_{2}$ emissions. However, it is recognised that introducing any new policy would require public participation and further discussions held between the different stakeholders (government, consumers and the automotive industry). This study could serve as an introduction to such further discussions.

\section{AUTHOR INFORMATION}

Johann du Plooy: CA (SA); MComm Taxation (SU); lecturer at Stellenbosch University in undergraduate auditing +2721 808 9426. E-mail: jduplooy@sun.ac.za (Corresponding author)

Rudie Nel: CA (SA); MComm Taxation (UP); lecturer at Stellenbosch University in undergraduate taxation and involved in Master's programme in taxation +2721 808 9079. E-mail: rnel@ sun.ac.za 


\section{REFERENCES}

1. Bandivadekar, A.P. (2008). Evaluating the impact of advanced vehicle and fuel technologies in US lightduty vehicle fleet. MA: Massachusetts Institute of Technology.

2. Black, A. \& Mitchell, S. (2002). Policy in the South African motor industry: Goals, incentives, and outcomes. Available from http://www.tips.org.za/files/561.pdf (Accessed on 23 June 2011).

3. Davis, W.B., Levine, M.D., Train, K. \& Duleep, K.G. (1995). Effects of feebates on vehicle fuel economy, carbon dioxide emissions, and consumer surplus. DOE/PO-0031. Washington, DC: Office of Policy, US Department of Energy.

4. DeCicco, J.M. (2006). Considerations for improving environmental information for US cars and light trucks. Paper presented at the $85^{\text {th }}$ Annual Meeting of the Transportation Research Board, 23 March, Washington, DC.

5. Greene, D.L., Patterson, P.D., Singh, M. \& Li, J. (2005). Feebates, rebates and gas-guzzler taxes: A study of incentives for increased fuel economy. Energy Policy, 33:757-775.

6. Hayashi, Y., Button, K. \& Nijkamp, P. (eds.). (1999). The Environment and Transport, Environment Analysis and Economic Policy, 4. Edward Elgar.

7. Hayashi, Y., Kato, H. \& Val, R.T. (2001). A model system for the assessment of the effects of vehicle and fuel green taxes on carbon dioxide emissions. Transportation Research, Part D6:123-139.

8. Johnson, K.C. (2006). Refunded emission taxes: A resolution to the cap-versus-tax dilemma for greenhouse gas regulation. Energy Policy, 35:3115-3118.

9. Karrim, Q. (2009). Motor industry welcomes Manuel's R870m boost. Mail\&Guardian Online. Available from http://www.mg.co.za/article/2009-02-11-motor-industry-welcomes-manuels-r870m-boost (Accessed on 10 October 2010].

10. Kunert, U. \& Hartmut, K. (2007). The diverse structures of passenger car taxation in Europe and the EU Commissions proposal for reform. Transport Policy, 14:306-316.

11. NAAMSA (National Association of Automobile Manufacturers of South Africa). (2010). Who we are. Available from http://www.naamsa.co.za/naamsa/ naamsaorg.htm (Accessed on 15 September 2010).

12. Nel, R. (2009). Proposed vehicle taxes in South Africa: What are the prospects of it achieving its purpose? Unpublished Master's thesis, University of Pretoria, Pretoria.

13. Nel, R. \& Nienaber, G. (2012). Tax Design to Reduce Passenger Vehicle CO2 Emissions. Meditari, 20(1).

14. Osborne, J. (2010). Emissions tax: The RMI's view. Automobil, August, 6.

15. Paul, D. (1997). Climate change: Facts, strategies, choices and innovations. Social Indicators Research, 42(2):117-149.

16. Peters, A., Mueller, M.G., De Haan, R. \& Scholz, W. (2008). Feebates promoting energy-efficient cars: Design options to address more consumers and possible counteracting effects. Energy Policy, 36:13551365.

17. PwC (PricewaterhouseCoopers). (2010). Appetite for change: Global business perspectives on tax and regulation for a low carbon economy. Available from http://www.pwc.com/gx/en/appetite-for-change (Accessed on 21 June 2010).

18. RSA (Republic of South Africa). (2010). Customs and Excise Act, No. 1964. Government Gazette 33514:1-4. Pretoria: Government Printers.

19. Rudman, M. (2008). Eco-friendly vehicles. Enterprise Risk, 2(5):14-15. Available from http://search.sabinet.co.za (Accessed on 10 September 2010).

20. Salgado, I. (2011). Roadmap set for cleaner fuel by 2017. Available from http://www.iol.co.za/business/business-news/roadmap-set-for-cleaner-fuel-by-2017-1.1038465 (Accessed on 9 March 2011).

21. SARS (South African Revenue Service). (2009). Budget tax proposal 2009/10. Available from http://www.sars.gov.za (Accessed on 9 September 2010).

22. Schipper, L., Fabian, H. \& Leather, J. (2009). Transport and carbon dioxide emissions: Forecasts, options analysis, and evaluation. ADB Sustainable Development Working Paper Series. Asian Development Bank.

23. Van der Merwe, C. (2010). SA businesses want clear environmental policy. Available from http://www.polity.org.za/article/sa-businesses-want-clear-environmental-regulation-policy-2010-03-04-1 (Accessed on 11 February 2011). 
24. Van Essen, H. (2010). International road and rail freight transport: Environmental impacts of increased activity levels. In: Globalisation, transport and the environment. OECD, 197-223 of Chapter 8.

25. World Resources Institute. (2000). World greenhouse gas emissions flow chart.Available from http://www.wri.org/chart/world-greenhouse-gas-emissions flow-chart (Accessed on 23 June 2011). 